\title{
Breath condenser coatings affect measurement of biomarkers in exhaled
} breath condensate

\author{
P.P. Rosias**, , C.M. Robroeks*, H.J. Niemarkt*, A.D. Kester", J.H. Vernooy", \\ J. Suykerbuyk*, J. Teunissen*, J. Heynens ${ }^{+}$, H.J. Hendriks*, \\ Q. Jöbsis* and E. Dompeling*
}

ABSTRACT: Exhaled breath condensate collection is not yet standardised and biomarker measurements are often close to lower detection limits. In the current study, it was hypothesised that adhesive properties of different condenser coatings interfere with measurements of eicosanoids and proteins in breath condensate.

In vitro, condensate was derived from a collection model using two test solutions (8-isoprostane and albumin) and five condenser coatings (silicone, glass, aluminium, polypropylene and Teflon). In vivo, condensate was collected using these five coatings and the EcoScreen ${ }_{\circledast}$ condenser to measure 8-isoprostane, and three coatings (silicone, glass, EcoScreen ${ }_{\mathbb{B}}$ ) to measure albumin.

In vitro, silicone and glass coatings had significantly higher albumin recovery compared with the other coatings. A similar trend was observed for 8-isoprostane recovery. In vivo, median (interquartile range) 8-isoprostane concentrations were significantly higher using silicone $\mathbf{( 9 . 2}$ (18.8) $\left.\mathrm{pg} \cdot \mathrm{mL}^{-1}\right)$ or glass $\left(3.0(4.5) \mathrm{pg} \cdot \mathrm{mL}^{-1}\right)$ coating, compared with aluminium $\left(0.5(2.4) \mathrm{pg} \cdot \mathrm{mL}^{-1}\right)$, polypropylene $\left(0.5(0.5) \mathrm{pg} \cdot \mathrm{mL}^{-1}\right)$, Teflon $\left(0.5(0.0) \mathrm{pg} \cdot \mathrm{mL}^{-1}\right)$, and EcoScreen ${ }_{\mathbb{B}}\left(0.5(2.0) \mathrm{pg} \cdot \mathrm{mL}^{-1}\right)$. Albumin in vivo was mainly detectable using glass coating.

In conclusion, a condenser with silicone or glass coating is more efficient for measurement of 8isoprostane or albumin in exhaled breath condensate, than EcoScreen $\mathbb{E}_{\mathbb{B}}$, aluminium, polypropylene or Teflon. Guidelines for exhaled breath condensate standardisation should include the most valid condenser coating to measure a specific biomarker.

KEYWORDS: Coating, cytokine, exhaled breath condensate, exhaled markers, isoprostanes, methodology

$\mathbf{T}$ he collection of exhaled breath condensate (EBC) has been rediscovered as a simple and noninvasive technique to measure mediators of airway inflammation. EBC consists not only of water vapor, but also contains aerosolised respiratory fluid droplets released from the respiratory epithelial lining fluid (ELF). These fluid droplets contain traces of nonvolatile solutes, which can be recovered in EBC samples [1]. EBC is collected by guiding and cooling exhaled air of a tidally breathing subject in a condenser system. EBC does not affect the airway; in contrast to bronchial biopsy, bronchoalveolar lavage and induced sputum. It can be obtained with minimal risk and minimal inconvenience for both adults and children [2]. Although the American Thoracic Society and European Respiratory Society Task Force on EBC recently published general methodological recommendations on the collection of EBC, there are still some methodological pitfalls and unresolved questions $[3,4]$. The most commonly used condensers are the EcoScreen ${ }^{\circledR}$ (Erich Jaeger GmbH, Hochberg, Germany), RTube ${ }_{\mathbb{A}}$ (Respiratory Research Inc., Charlottesville, VA, USA) and home-made glass or Teflon devices.

Two important groups of inflammatory biomarkers in EBC of adults and children are eicosanoids and cytokines [3-10]. Eicosanoids, such as 8-isoprostane, are formed by lipid peroxidation of arachidonic acid during oxidative stress [11]. 8-Isoprostane (molecular weight 354 Dalton) can be measured in EBC of adults and children, although reproducibility remains controversial $[12,13]$. Cytokines are low molecular weight $(<80,000$ Dalton) proteins involved in mediating inflammation and tissue repair. Reports on the detection of cytokines in EBC are incidental, with the exception of a report on interleukin (IL)- 6 by
AFFILIATIONS

Depts of *Paediatric Pulmonology, and

${ }^{\text {\#}}$ Respiratory Medicine, University Hospital Maastricht, and

"Dept of Methodology and Statistics, Maastricht University

Maastricht, and

+Dept of Paediatrics, Maasland Hospital, Sittard, The Netherlands.

CORRESPONDENCE

P.P. Rosias

Dept of Paediatrics

Maasland Hospital

P0 Box 5500

6130 MB Sittard

The Netherlands

Fax: 31464588623

E-mail: p.rosias@orbisconcern.nl

Received:

September 222005

Accepted after revision:

July 072006 
CARPAGNANO et al. [14]. Albumin, a protein with a similar molecular weight $(66,000$ Dalton), was demonstrated in induced sputum and EBC in asthmatic subjects $[15,16]$.

The reported mean biomarker values in EBC are usually situated in the lower range of detection $[3,6]$. It may be that the biomarker concentration in ELF is intrinsically low or that only minor amounts are released from ELF into exhaled air. An alternative explanation may be that adhesive properties of different inner condenser coatings interfere with the detection of various inflammatory markers in $\operatorname{EBC}[13,17]$.

The aim of the present study was to investigate the influence of different inner condenser coating surfaces (silicone, borosilicate glass, aluminium, polypropylene, Teflon and EcoScreen ${ }_{\mathbb{8}}$ with a Teflon-like coating) on the measurement of 8-isoprostane and albumin in EBC using both an in vitro and in vivo approach.

\section{METHODS}

\section{In vitro studies}

In close collaboration with the Dept of Instrument Development Engineering \& Evaluation of the University of Maastricht (Maastrict, the Netherlands) an in vitro EBC collection model was developed consisting of a rechargeable condenser system connected in series with an ultrasonic nebuliser (Ultra-NebTM2000; DeVilbiss, Langen, Germany) and a ventilator (Servo-900C; Siemens, Solna, Sweeden; fig. 1a). The rechargeable condenser system consisted of a fixed $30-\mathrm{cm}$ metal outer cylinder (diameter $4 \mathrm{~cm}$; Felix Philips Maatmetaal BV, Maastricht, the Netherlands) connected to a countercurrent circulating ice-water pump at $0^{\circ} \mathrm{C}$, and an exchangeable inner cylinder (diameter $2 \mathrm{~cm}$ ), as shown in figure $1 \mathrm{~b}$. The exchangeable inner cylinder was available in five different coatings: silicone, borosilicate glass, aluminium, polypropylene and Teflon. The borosilicate glass tubes were manufactured by Louwers Glass and Ceramic Technologies (Hapert, the Netherlands). Identical glass tubes were coated internally with silicone by Imbreglon BV (Beuningen, the Netherlands). The aluminium tubes were manufactured by Felix Philips Maatmetaal BV. Identical aluminium tubes were coated internally with Tempcoat 1011F (Teflon) by Imbreglon BV. The polypropylene tubes were produced by Applikon BV (Schiedam, the Netherlands). The outer surface of the inner cylinder was in direct contact with the counter current circulating ice water, while its inner surface was in direct contact with the exhaled breath or the volatile substances derived from the nebuliser and propelled by the ventilator. The nebuliser was filled with a biomarker test solution $\left(42 \mathrm{pg} \cdot \mathrm{mL}^{-1}\right.$ 8-isoprostane or $0.1 \mathrm{mg} \cdot \mathrm{mL}^{-1}$ albumin in a $22 \mathrm{~mL}$ saline $0.9 \%$ solution), which was nebulised and propelled by a ventilator through the condenser system, simulating tidal breathing for 15 min (ventilator settings: inspiration time 33\%, respiratory frequency $20 \cdot \mathrm{min}^{-1}$, tidal volume $200 \mathrm{~mL}$ ). The construction of the collection device only allowed contact between the propelled air/exhaled breath and one specific type of inner coating that was chosen at that moment (fig. 1b). The condensate was collected at the open end of the condenser device directly into vials. For each coating, 15 experiments were performed (see the power analysis in the Statistics section). After each experiment, the coated tubes were rinsed repeatedly with bi-distilled water and subsequently dried at room air for $\geqslant 24 \mathrm{~h}$. Multiple coated tubes of each type were available to allow a smooth continuation of the experiments, without any delay due to the drying of the coated tube that was used in the preceding test. The biomarker condensate recovery percentage was defined as the ratio of biomarker concentration in condensate, to biomarker concentration in the test solution.

\section{In vivo 8-isoprostane study}

As 8-isoprostane has been detected in EBC of healthy subjects, the influence of condenser coatings on 8-isoprostane measurements in vivo was studied in 28 healthy volunteers (see the power analysis in the Statistics section). Standardised questionnaires from the International Study of Asthma and Allergies in Childhood (ISAAC) were completed to exclude the presence of respiratory infections, asthma or allergic disease [18]. Each subject was asked to breathe tidally, while wearing a nose-clip, into a mouthpiece connected to a two-way non-rebreathing valve that was in turn connected by tubing to the condenser. The two-way valve and tubing also served as a saliva trap. In this way, each subject exhaled for $15 \mathrm{~min}$ along
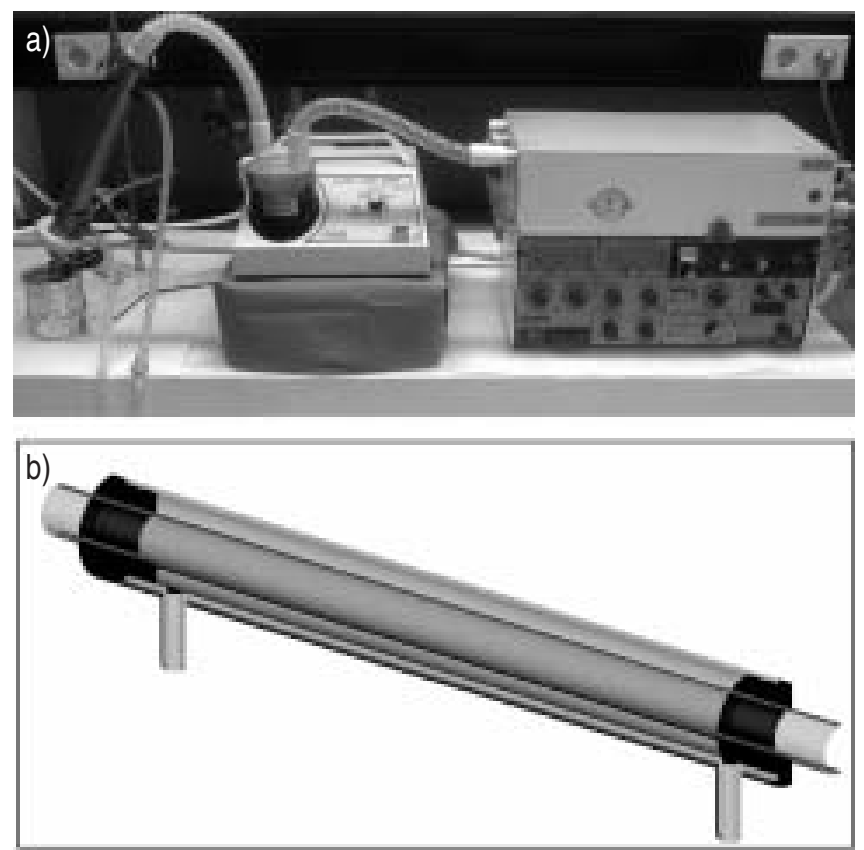

FIGURE 1. a) In vitro exhaled breath condensate collection model consisting of a rechargeable condenser system connected in series with an ultrasonic nebuliser and a ventilator. The nebuliser could be filled with a test solution of a known concentration of 8-isoprostane or human albumin. The nebulised test solution is propelled by the ventilator through the condenser system. b) Schematic representation of the rechargeable condenser system, which consisted of a fixed 30-cm metal outer cylinder (diameter $4 \mathrm{~cm}$ ), connected to a counter-current circulating ice-water pump at $0^{\circ} \mathrm{C}$, and an exchangeable inner cylinder $(2 \mathrm{~cm})$. The exchangeable inner cylinder was available in five different coatings: silicone, borosilicate glass, aluminium, polypropylene and Teflon. The outer surface of this inner cylinder was in direct contact with the counter-current circulating ice water, while its inner surface was in direct contact with the exhaled breath or the volatile substances derived from the nebuliser and propelled by the ventilator. 
each of the five coatings in random order, as well as along the EcoScreen $_{\Re}$, a commercial condenser system with a modified Teflon coating.

\section{In vivo albumin study}

In contrast to 8-isoprostane, the in vivo albumin study was planned in asthmatic children, as the chance of positive albumin detection is larger in a disease population [16]. EBC was collected in 40 asthmatic children. Inclusion criteria were doctor-diagnosed mild or moderate persistent asthma requiring daily inhaled corticosteroids for $\geqslant 6$ months [19]. Exclusion criteria were clinical evidence of respiratory infection 4 weeks prior to study, and comorbidity (mental retardation, respiratory tract anomalies or cardiac defects). In contrast to the in vivo 8-isoprostane study, the asthmatic children in the albumin study were only asked to exhale tidally along one type of coating (silicone, glass or EcoScreen $\mathbb{\circledR}$ ), to allow parallel group comparison. Children were randomly allocated to one out of three coating groups.

\section{Sample processing}

Immediately after collection, the condensate samples were snap-frozen at $-78^{\circ} \mathrm{C}$ using dry ice and subsequently stored at $-80^{\circ} \mathrm{C}$ until analysis. A reaction mixture of the immunoassay was not added to the condensate samples before storage. In order to maintain optimal condensate sample preservation, for subsequent 8-isoprostane and albumin measurement, samples were analysed within $6-8$ weeks of storage at $-80^{\circ} \mathrm{C}$. Samples were only defrosted once, at the time of analysis. All isoprostane and albumin concentrations were determined in duplicate by specific enzyme immunoassay (Cayman Chemical $₫$, Ann Arbor, MI, USA) and sandwich ELISA respectively [16]. The lower limit of detection was 2.45 and $32 \mathrm{pg} \cdot \mathrm{mL}^{-1}$, respectively.

\section{Statistics}

The condensate recovery percentage of a specific coating was the primary outcome measure of the in vitro experiments. Mean values and standard deviations of recovery percentages were calculated. A comparison between the five different coatings and between the two biomarkers in vitro was made by means of univariate ANOVA. Power analysis demonstrated a required number of 15 experiments in each group, in order to detect a relevant difference between coatings of $25 \%$ with a power of $90 \%$, an alpha of 0.05 and an SD of $20 \%$ (the SD in the first set of 10 experiments was $20 \%$ ).

In the in vivo studies, the number of positive detections, median and mean values, SD (based on the first 15 subjects) and interquartile ranges (IQRs) were calculated. Power calculation showed that 23 patients are needed to detect a $10 \%$ difference in biomarker concentration with a power of $90 \%$, an alpha of 0.05 and an SD of $14 \%$ (paired t-test). Due to a number of negative detections, the Wilcoxon paired signed-rank test was used to compare data within subjects. A sample with negative detection is not considered as a missing value, because it actually informs that the measurement of a marker was below the detection limit. Therefore, the negative detection is given an arbitrary value of 0.5 .

\section{Ethics}

All subjects gave written informed consent. The study was approved by the Medical Ethics Committee of the University Hospital of Maastricht.

\section{RESULTS}

\section{In vitro study of albumin and 8-isoprostane}

Albumin was detected in $93 \%$ of condensate samples (fig. 2). Overall, the mean albumin recovery in condensate was only $52 \%$ using this experimental model. The albumin recovery percentages varied from $22.9 \%$ using a Teflon coating, to 69.4 and $94.7 \%$ using a glass and silicone coating, respectively. The albumin recovery percentage was significantly higher using the silicone and glass coating compared with the other coatings $(p=0.03$, ANOVA). No other statistically significant differences were present.

Isoprostane was detected in 77 out of 78 condensate samples (fig. 3). The isoprostane recovery percentages varied from $93.1 \%$ using an aluminum coating to 102.7 and $105.6 \%$ using a glass and silicone coating, respectively, which did not reach statistical significance (ANOVA, F-test, $p=0.09$ ). Overall, the mean 8-isoprostane recovery in condensate was close to $100 \%$, which was significantly higher than the overall albumin recovery percentage of $52 \%$ (ANOVA, $\mathrm{p}=0.0001$ ).

\section{In vivo study of 8-isoprostane}

Subject characteristics are shown in table 1. Isoprostane was detected in $41 \%$ of condensate samples (fig. 4). For each coating, the number of positive/negative isoprostane detections in EBC was 23/five (silicone), 15/13 (glass), 11/17 (aluminium), seven/21 (polypropylene), five/23 (Teflon) and

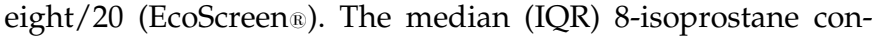
centrations in EBC in 28 healthy subjects ranged from $0.5 \mathrm{pg} \cdot \mathrm{mL}^{-1}$ for aluminium (IQR $\left.0.5-2.9\right)$, polypropylene $(0.5-$ $1.0)$, Teflon $(0.5-0.5)$ and the EcoScreen ${ }_{\circledast}(0.5-2.5)$, to $3.0(0.5-$ 5.0) $\mathrm{pg} \cdot \mathrm{mL}^{-1}$ and $9.2(5.1-23.9) \mathrm{pg} \cdot \mathrm{mL}^{-1}$ for the glass and

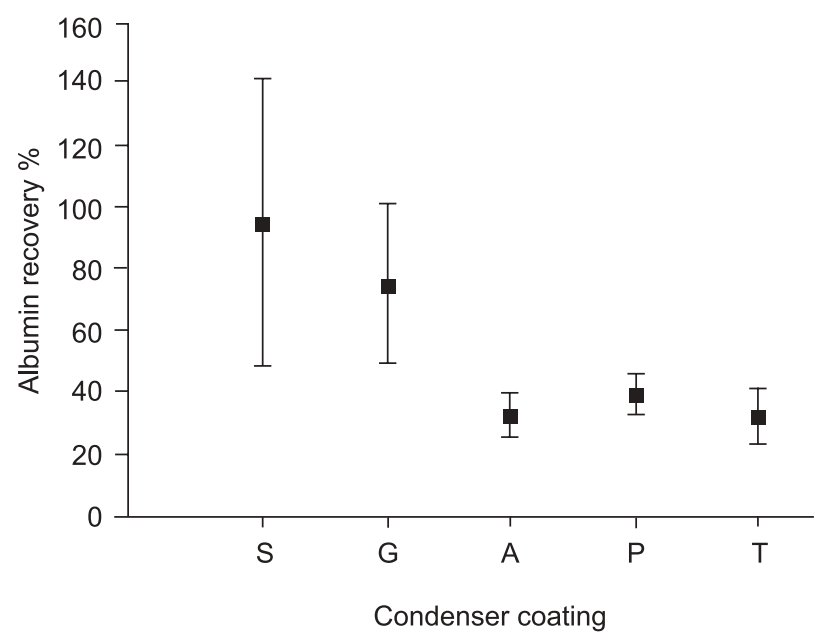

FIGURE 2. In vitro albumin condensate recovery percentages using five different condenser coatings. Albumin was detected in 65 out of 70 condensate samples (one negative sample using glass $(G)$, four negative samples using Teflon $(T)$ ). Silicone (S) and glass coatings had significantly higher albumin condensate recovery percentages compared with the other coatings $(p=0.03)$. Data are presented as mean \pm SEM. A: aluminium; P: polypropylene. 


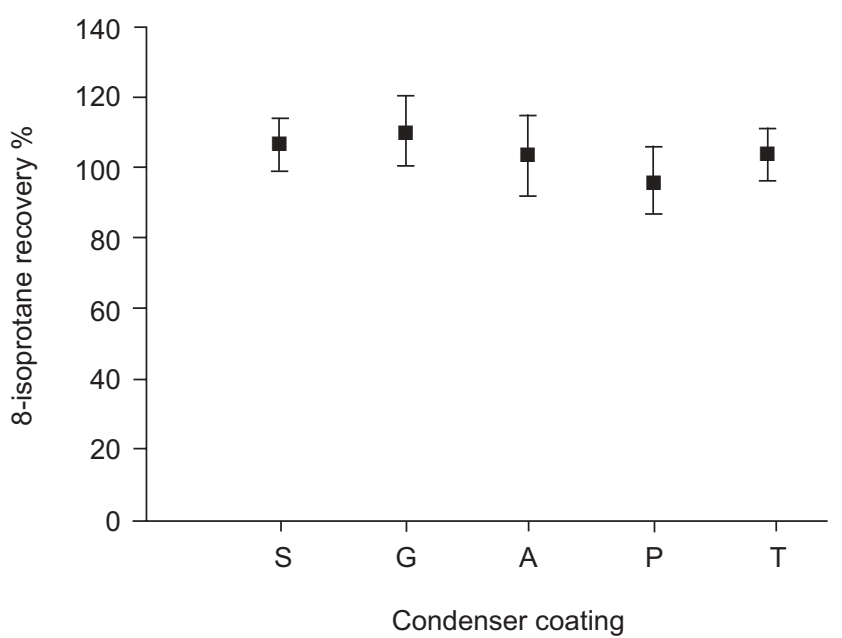

FIGURE 3. In vitro 8-isoprostane condensate recovery percentages using five different condenser coatings. Isoprostane was detected in all $(n=78)$ but one condensate sample (one negative sample using polypropylene (P)). Silicone (S) and glass $(G)$ coatings had higher 8-isoprostane condensate recovery percentages, although statistically not different compared with the other coatings $(p=0.09)$. Data are presented as mean \pm SEM. A: aluminium; T: Teflon.

silicone coating, respectively. EBC 8-isoprostane concentrations were significantly higher using silicone coating compared with each of the other coatings $(p<0.001$, Wilcoxon signedrank test). Similarly, glass coating was better than polypropylene, Teflon and the EcoScreen ${ }^{\circ}(p<0.02$, Wilcoxon test). The 8isoprostane concentrations obtained with aluminium, polypropylene, Teflon and the EcoScreen $\mathbb{B}$ did not differ from each other $(p=0.763$, Friedman test). As median values and IQRs in smokers and nonsmokers were comparable, smoking was not a confounder in this study.

\section{In vivo study of albumin}

Subject characteristics are shown in table 1. Albumin was detected in eight out of 40 condensate samples (0.04$\left.0.24 \mu \mathrm{g} \cdot \mathrm{mL}^{-1}\right)$. Positive detections were almost exclusively found with a glass coating: seven out of 13 samples using a glass coating, one out of 14 samples using the EcoScreen ${ }^{\circledR}$ and none out of 13 samples using a silicone coating $(p<0.008$, Chisquared test). Disease stability, lung function and atopic status were not confounding factors, as these characteristics were equally distributed across the three coating groups (data not shown).

\begin{tabular}{lcc} 
TABLE 1 & Subject characteristics & \\
& $\begin{array}{c}\text { Healthy subjects } \\
\text { 8-isoprostane study }\end{array}$ & $\begin{array}{c}\text { Asthmatic subjects } \\
\text { albumin study }\end{array}$ \\
\hline Subjects & 28 & 40 \\
Male & 10 & 27 \\
Smoking & 5 & 0 \\
Atopic & 0 & 36 \\
Age yrs & $\mathbf{2 6}(\mathbf{2 0 - 5 7 )}$ & $\mathbf{1 1}(\mathbf{5 - 1 7 )}$ \\
\hline &
\end{tabular}

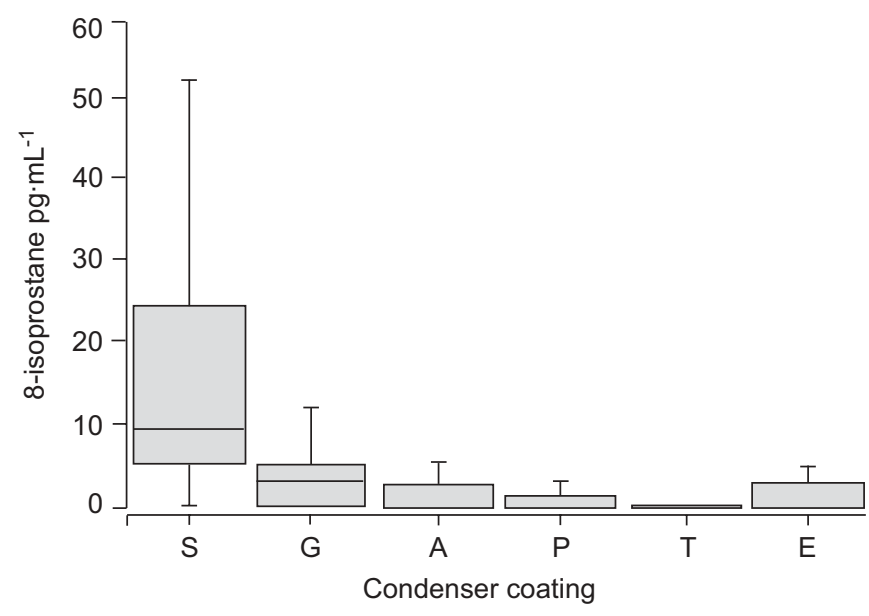

FIGURE 4. In vivo 8-isoprostane condensate concentrations in 28 healthy volunteers using six different condenser coatings. Isoprostane was detected in 69 out of 168 condensate samples. Isoprostane condensate concentrations were significantly higher using a silicone $(S)$ coating $(p<0.001)$ or a glass $(G)$ coating $(p<0.02)$ compared with the other coatings. Data are presented as median \pm interquartile range. A: aluminium; P: polypropylene; T: Teflon; E: EcoScreen® (Erich Jaeger $\mathrm{GmbH}$, Hochberg, Germany) condenser.

\section{DISCUSSION}

Both in vitro and in vivo, the present study demonstrates a significant influence of the different inner condenser coatings on the measurement of eicosanoid and protein biomarkers in EBC. In particular, silicone and glass coatings were superior to aluminum, polypropylene and Teflon with respect to the recovery of both 8-isoprostane and albumin in EBC in vitro and in vivo.

A careful MEDLINE online database search for all available studies on 8-isoprostane in EBC, demonstrates data in line with the results of the present study. When considering an identical assay (enzyme- or radio-immunoassay), higher 8-isoprostane concentrations were reported using a glass coating compared with the EcoScreen ${ }^{\circledR}$. In vivo using the EcoScreen ${ }^{\circledR}$, present 8isoprostane concentrations (median (range) 3.5 (2.5-4.8) pg. $\mathrm{mL}^{-1}$ ) were comparable to the values reported by VAN HOYDONCK et al. [20] (4.6 (3.9-7.7) $\left.\mathrm{pg} \cdot \mathrm{mL}^{-1}\right)$. Specific data on detectability of isoprostane in EBC are scarce. The current study reports $41 \%$ of detectability in volunteers, which is in agreement with the findings (36\%) of VAN HOYDONCK et al. [20] in smokers.

In vitro, the overall mean albumin condensate recovery percentage was 52\%, compared with $100 \%$ isoprostane recovery. This suggests a more difficult condensate recovery of protein biomarkers, which is supported by the present limited number of positive albumin detections in vivo. Also, the relatively few positive studies on cytokines or proteins in EBC versus several positive reports on 8-isoprostane and leukotrienes in EBC may suggest that the recovery of proteins in EBC is less easy than that of eicosanoids. Recently, TUFVESSONand BJERMER [21] also showed that the detection of eicosanoids and cytokines in EBC in asthmatic subjects may be facilitated by coating of all collection surfaces with Tween 20 and bovine serum albumin, respectively, combined with vacuum-centrifugation of 
condensate samples. Moreover, 30-fold differences in condensate levels of IL-4 in asthmatic children were found using different condenser systems and enzyme immunoassays [22-24]. The latter finding indicates that variability of biomarker levels in condensate may also be attributed to intrinsic analytical problems of currently used immunoassays, as illustrated recently for thromboxane-A2 metabolite measurements in EBC [24].

In vitro, the mean 8-isoprostane condensate recovery percentages did not differ significantly between the condenser coatings $(p=0.09)$. One explanation may be the higher overall mean condensate recovery of isoprostane, in contrast to albumin, which may illustrate a different behaviour of these biomarkers during the expiratory phase of the EBC collection. In turn, this may be a reflection of difficulties experienced by molecules with a higher molecular weight, in their transition from respiratory fluid droplets and exhaled air, to condensate. Conversely, overload in the 8-isoprostane in vitro tests seems unlikely when considering that the absolute amount in the test tubes must have been very close to concentrations found in vivo. Hence, it may be that the nebuliser set-up is producing 8isoprostane aerosols that are more effectively condensed as compared to the real EBC in vivo. Therefore, further studies on the optimal condenser coating should always include in vivo experiments.

The EcoScreen ${ }$ is a commonly used and commercially available condenser system with distinctive physical characteristics. In contrast to the current authors' collection system and the RTube ${ }^{\circledR}$, which collect EBC in the liquid phase, the EcoScreen $_{\circledR}$ collects EBC mainly as ice, which may be associated with more drastic freeze-thaw cycles that can affect the molecules collected $[23,25]$. The EcoScreen $\mathbb{R}$ is a condenser system based on a modified inner Teflon coating. The 8isoprostane EBC concentrations were similar for the EcoScreen ${ }^{\circledR}$ and the Teflon coating, suggesting no significant influence from the specific physical characteristics of the EcoScreen ${ }^{\circledR}$ condenser device in vivo.

A different design of the in vivo 8-isoprostane and albumin study was chosen, although ideally both study parts should have had a similar design. However, considerations in support of differing designs were decisive: 1) subjects with asthma are more likely to have positive albumin detection in EBC than healthy controls [16]; and 2) a 90-min EBC collection period, like in the in vivo 8-isoprostane study, was neither realistic nor feasible in the asthmatic children of the in vivo albumin study. Therefore, a between-subject (parallel groups), rather than an intra-subject, comparison of condenser coatings was chosen for the in vivo albumin study.

Standardisation of the EBC collection method implicates more than applying one identical collection technique. It implicates the development of a condenser system with the highest and least varying recovery percentages. Optimisation of condensate recovery percentages may lead to an improvement of biomarker reproducibility. Therefore, the current authors recommend the use of a condenser system with an inner glass or silicone coating for the measurement of 8-isoprostane and albumin in EBC. The reproducibility of measurements by using different condenser coatings should be evaluated in vivo.
An explanation for this superiority of glass and silicone coatings may be that water acts as a bipolar vehicle. The $\mathrm{pH}$ of exhaled breath ranges from 6.50-7.80, whereas the isoelectrical point of human albumin is situated at $\mathrm{pH} 4.80[3,26]$. In other words, at higher $\mathrm{pH}$ values (such as reported in $\mathrm{EBC}$ ) albumin acts as a negatively charged molecule. Therefore, the negatively charged albumin in exhaled breath may be repulsed by glass that is also negatively charged. This may promote the recovery of albumin in EBC. In contrast, the same albumin molecule may be attracted by aluminium metal ions that are positively charged. This may hamper the recovery of albumin in EBC in this case. Furthermore, 8-isoprostane acts in an extremely hydrophobic manner and will stick to neutral surfaces (such as Teflon) in the presence of aqueous solutions, to lipids and to detergents.

Not only adhesive and electrical properties of the condensation equipment may affect whether a compound is collected in EBC, but also issues such as the length of the condensation tube, thermal conduction of the coating, solute solubility, volatility, and its dissociation constant $\left(\mathrm{pK}_{\mathrm{a}}=-\log \mathrm{K}_{\mathrm{a}}\right)$.

Finally, these findings in 8-isoprostane and albumin do not necessarily hold for all other biomarkers. Every biomarker has its own chemical and physical characteristics. Currently, one may speculate that most eicosanoids act in a similar way. Likewise, small proteins such as cytokines may act differently from eicosanoids, but similarly when comparing one cytokine to another.

The present authors conclude that a condenser system with a silicone or glass coating is more efficient for the measurement of 8-isoprostane or albumin in exhaled breath condensate, compared with the EcoScreen $₫$, or condensers with aluminum, polypropylene or Teflon coating. The increased efficiency of the borosilicate glass and silicone coatings may be due to less adhesive properties resulting in more biomarker recovery in the condensate. To establish methodological standardisation of the collection of exhaled breath condensate, the most valid and inert condenser coating has to be applied for the measurement of a specific inflammatory biomarker.

\section{ACKNOWLEDGEMENTS}

The authors wish to thank: M. Dentener and R. Cloots for their technical support in the analysis of the albumin condensate samples (Dept Respiratory Medicine, University Hospital of Maastricht); M. Hadfoune for his technical support in the analysis of the 8-isoprostane condensate samples (General Surgery, Nutrition and Toxicology Research Institute Maastricht, Maastricht University); P. Laeven for his technical support in the development of the rechargeable condenser system (Dept of Instrument Development Engineering \& Evaluation, University of Maastricht); J. Sijbrandij for her statistical support (Dept of Epidemiology, University of Maastricht); and last but not least the volunteers for their participation.

\section{REFERENCES}

1 Scheideler L, Manke HG, Schwulera U, Inacker O, Hämmerle H. Detection of non-volatile macromolecules 
in breath. A possible diagnostic tool? Am Rev Respir Dis 1993; 148: 778-784.

2 Baraldi E, Ghiro L, Piovan V, Carraro S, Zacchello F, Zanconato S. Safety and success of exhaled breath condensate collection in asthma. Arch Dis Child 2003; 88: 358-360.

3 Rosias PP, Dompeling E, Hendriks HJ, Heijnens JW, Donckerwolcke RA, Jöbsis Q. Exhaled breath condensate in children: pearls and pitfalls. Pediatr Allergy Immunol 2004; 15: 4-19.

4 Horváth I, Hunt J, Barnes PJ, on behalf of the ATS/ERS Task Force. Exhaled breath condensate: methodological recommendations and unresolved questions. Eur Respir J 2005; 26: 523-548.

5 Mutlu GM, Garey KW, Robbins RA, Danziger LH, Rubinstein I. Collection and analysis of exhaled breath condensate in humans. Am J Respir Crit Care Med 2001; 164: 731-737.

6 Kharitonov SA, Barnes PJ. Exhaled markers of pulmonary disease. Am J Respir Crit Care Med 2001; 163: 1693-1722.

7 Montuschi P, Barnes PJ. Analysis of exhaled breath condensate for monitoring airway inflammation. Trends Pharmacol Sci 2002; 23: 232-237.

8 Hunt J. Exhaled breath condensate: an evolving tool for non-invasive evaluation of lung disease. J Allergy Clin Immunol 2002; 110: 28-34.

9 Antczak A, Gorski P. Markers of pulmonary diseases in exhaled breath condensate. Int J Occup Med Environ Health 2002; 15: 317-323.

10 Jöbsis Q, Rosias PPR. Analysis of exhaled breath condensate in children. In: Montuschi P, ed. New Perspectives in Monitoring Lung Inflammation: Analysis of Exhaled Breath Condensate. London, CRC Press, 2005; pp. 105-111.

11 Wood LG, Gibson PG, Garg ML. Biomarkers of lipid peroxidation, airway inflammation and asthma. Eur Respir J 2003; 21: 177-186.

12 Montuschi P, Ragazzoni E, Valente S, et al. Validation of 8isoprostane and prostaglandin E2 measurements in exhaled breath condensate. Inflamm Res 2003; 52: 502-507.

13 Rahman I. Reproducibility of oxidative stress biomarkers in breath condensate: are they reliable? Eur Respir J 2004; 23: 183-184.

14 Carpagnano GE, Resta O, Foschino-Barbaro MP, et al. Exhaled interleukin-6 and 8-isoprostane in chronic obstructive pulmonary disease: effect of carbocysteine lysine salt monohydrate (SCMC-Lys). Eur J Pharmacol 2004; 505: 169-175.

15 Van Rensen ELJ, Hiemstra PS, Rabe KF, Sterk PJ. Assessment of microvascular leakage via sputum induction. Am J Respir Crit Care Med 2002; 165: 1275-1279.

16 Rosias PP, Dompeling E, Dentener MA, et al. Childhood asthma: exhaled markers of airway inflammation, asthma control score and lung function tests. Pediatr Pulmonol 2004; 38: 107-114.

17 Rosias PPR, Robroeks C, Hendriks J, Dompeling E, Jöbsis Q. Exhaled breath condensate: a space odyssey, where no one has gone before. Eur Respir J 2004; 24: 189-190.

18 Asher MI, Keil U, Anderson HR, et al. International study of asthma and allergies in childhood (ISAAC): rationale and methods. Eur Respir J 1995; 8: 483-491.

19 Global Strategy for Asthma Management and Prevention. NHLBI/WHO Workshop report Publication No. 95-3659. National Heart Lung and Blood Institute. Bethesda, National Institutes of Health, 1995.

20 Van Hoydonck PG, Wuyts WA, Vanaudenaerde BM, Schouten EG, Dupont LJ, Temme EH. Quantitative analysis of 8-isoprostane and hydrogen peroxide in exhaled breath condensate. Eur Respir J 2004; 23: 189-192.

21 Tufvesson E, Bjermer L. Methodological improvements for measuring eicosanoids and cytokines in exhaled breath condensate. Respir Med 2006; 100: 34-38.

22 Shahid SK, Kharitonov SA, Wilson NM, Bush A, Barnes PJ. Increased interleukin- 4 and decreased interferon-gamma in exhaled breath condensate of children with asthma. Am J Respir Crit Care Med 2002; 165: 1290-1293.

23 Leung TF, Wong GW, Ko FW, et al. Analysis of growth factors and inflammatory cytokines in exhaled breath condensate from asthmatic children. Int Arch Allergy Immunol 2005; 137: 66-72.

24 Huszar E, Szabo Z, Jakab A, Barta I, Herjavecz I, Horvath I. Comparative measurement of thromboxane A2 metabolites in exhaled breath condensate by different immunoassays. Inflamm Res 2005; 54: 350-355.

25 Leung TF, Li CY, Lam CW, et al. The relation between obesity and asthmatic airway inflammation. Pediatr Allergy Immunol 2004; 15: 344-350.

26 Komatsu T, Oguro Y, Teramura Y, et al. Physicochemical characterization of cross-linked human serum albumin dimer and its synthetic heme hybrid as an oxygen carrier. Biochim Biophys Acta 2004; 1675: 21-31. 